\title{
Low vaccination coverage for human papillomavirus disease among young men who have sex with men, France, 2019
}

Giuseppina Ortu ${ }^{1,2}$, Anne-Sophie Barret ${ }^{1}$, Kostas Danis ${ }^{1}$, Lucie Duchesne ${ }^{1}$, Daniel Levy-Bruhl1 ${ }^{1}$, Annie Velter ${ }^{1}$

1. Santé Publique France, Saint Maurice, France

2. European Programme for Intervention Epidemiology Training (EPIET), European Centre for Disease Prevention and Control (ECDC), Stockholm, Sweden

Correspondence: Giuseppina Ortu (giuseppina_ortu@outlook.com)

Citation style for this article:

Ortu Giuseppina, Barret Anne-Sophie, Danis Kostas, Duchesne Lucie, Levy-Bruhl Daniel, Velter Annie. Low vaccination coverage for human papillomavirus disease among young men who have sex with men, France, 2019. Euro Surveill. 2021;26(50):pii=2001965. https://doi.org/10.2807/1560-7917.ES.2021.26.50.2001965

Background: In France, human papillomavirus (HPV) vaccination has been recommended in 2016 for men who have sex with men (MSM) up to age 26 years. Aim: We aimed to estimate HPV vaccine coverage in $18-28$ year-old MSM and identify uptake determinants. Methods: We collected data on socio-demographic characteristics, sexual behaviour, sexually transmitted diseases (STI) screening and vaccination uptake using a voluntary cross-sectional online survey conducted in 2019 targeting MSM. We calculated coverage of at least one dose of HPV vaccine and prevalence ratios (PR) of determinants with $95 \%$ confidence intervals (Cl) using Poisson regression. Results: Of 9,469 respondents (age range: $18-28$ years), $15 \%$ (95\% Cl: 14-16) reported being vaccinated for HPV. Coverage was significantly higher among MSM $<24$ years (PR: 1.25; $95 \% \mathrm{Cl}$ : 1.13-1.39), with education level below university degree (PR: 1.12; 95\% Cl: 1.08-1.32), living in rural areas (PR: 1.21; $95 \% \mathrm{Cl}: 1.08-1.36)$, attending sex parties (PR: 1.12; 95\% Cl: 1.03-1.33), using HIV-related biomedical prevention methods (PR: 1.31; 95\% Cl: 1.12-1.54), with STI diagnosis (PR: 1.22; $95 \%$ Cl: 1.08-1.38) and with hepatitis A or B vaccination (PR: $4.56 ; 95 \% \mathrm{Cl}: 3.63-5.81$ vs PR: $3.35 ; 95 \% \mathrm{Cl}$ : 2.53-4.44). Conclusions: The HPV vaccination uptake among MSM in France was not satisfactory. It was higher among MSM benefitting from other vaccinations and biomedical preventive methods against HIV, suggesting a synergistic effect of the national preventive sexual health recommendations for MSM. Further efforts to improve HPV vaccination coverage targeting MSM are warranted.

\section{Introduction}

Human papilloma virus (HPV) is a sexually transmitted infection that can lead to anal, genital and oral cancers. Approximately $4.5 \%$ of all new cancers cases per year worldwide (roughly 630,000 ) are attributable to HPV, with an estimated $8.6 \%$ in women and $0.8 \%$ in men [1]. Biological risk factors such as immunosuppression (e.g. in HIV patients [2]) and high-risk sexual behaviour $[3,4]$ increase the risk of HPV infection and development of premalignant lesions and cancers. In men who have sex with men (MSM), genital and anal warts are common and incidence of HPV-related anal cancers is high in this population compared with heterosexual individuals $[3,5]$. Moreover, the higher incidence of HIV in MSM compared with general population and the increased risk of HPV in HIV-positive individuals, makes the MSM population even more at risk of HPVrelated diseases.

There are 13 types of HPV considered at high risk of causing genital and anal premalignant lesions and cancers. Most frequently responsible for cancers are HPV $16 / 18$ (87\% of all anal cancers) [1]. Several vaccines have been developed to protect against HPV, among them the 4-valent recombinant vaccine and the most recent 9-valent vaccine [6]. It is estimated that the nine HPV types targeted by the 9 -valent vaccines contribute to $95 \%$ of anal cancers [1]. In the last decade, most European countries have introduced HPV vaccination, generally via school based programmes or primary healthcare services [7], targeting pre-adolescent girls; other European countries have started vaccination in boys and girls, aiming at an universal coverage [6]. In some countries where vaccination was initiated only in girls, the vaccination programme was subsequently extended to groups at high risk of cancers related to the HPV types targeted by this vaccine, e.g. MSM.

Among a total of 352,000 estimated new cancer cases reported in France in 2015, an estimated 6,333 were attributable to HPV, of which $28 \%$ affected men [8]. France started the HPV immunisation programme in 2007 with the vaccination of girls at age 14 years and catch-up vaccination for girls and young women aged 15-23 years [9]. Later on, it was amended to include immunocompromised or asplenic individuals of both sexes and in 2016, extended to MSM up to the age of 
26 years [10-14]. In 2017, a national strategy on sexual health (Strategy Nationale de Sante Sexuelle 20172030 [15]) was launched, aiming to achieve 60\% HPV vaccine coverage by 2023 and $80 \%$ HPV vaccine coverage by 2030 among adolescent girls. At that time, vaccination of boys was not considered cost-effective in the French context [13]; however, in 2019, the Collège de la Haute Autorité de santé, recommended extending HPV vaccination to this group, a recommendation that took effect in January 2021 [16].

Since 2016, MSM and other targeted groups can access vaccination via family physicians, sexual health practitioners and primary healthcare facilities; however, the 2016 High Council for Public Health (Haute Autorité de Santé) recommendation about HPV vaccination for men emphasised the need to offer the HPV vaccine free of charge to MSM also in sexual health centres (Centre Gratuit d'Information, de Dépistage et de Diagnostics, CeGIDD) $[17,18]$, a recommendation that was put into practice in the same year [19].

To date, information on HPV vaccination uptake in MSM population in France is limited. The CeGIDD reported the number of HPV vaccination doses administered between 2016 and 2018 [19]; however, absence of data on the actual population of MSM accessing these centres made it impossible to estimate vaccination coverage in these facilities.

In 2019, a cross-sectional study targeting MSM, called the 'Enquête rapport au sexe' (ERAS), was performed in France to describe the trends of the adoption of different methods of HIV prevention [20]. In this survey, questions related to the vaccination status and the uptake of screening for sexually transmitted infections were introduced. We aimed to estimate the HPV vaccination uptake among MSM aged between 18 and 28 years in France and to identify the socio-demographic factors and health determinants associated with vaccination in MSM since the recommendations were introduced.

\section{Methods}

\section{Study overview and data collection}

We used data from the ERAS cross-sectional study performed in France from 16 February to 31 March 2019. Details of the methodology used for this survey have been already published elsewhere [20].

In brief, a questionnaire was posted online on different networks such as gay dating (e.g. Grindr, Scruff, Hornet) or information websites (Têtu, Gayvox.fr, AgendaQ), generally targeting gay communities. In addition, the survey was distributed via other platforms such as Facebook and was available via links in websites accessed when using keywords related to homosexuality and encounters between men. Participation criteria were men 18 years and older.

\section{Inclusion criteria}

We included in our analysis all participants that declared to be 'homosexual' or 'bisexual' or reported having at least one male sexual intercourse during their life. We selected for our analysis all MSM resident in metropolitan France and overseas French departments and all those up to the age of 28 years. This age was chosen to allow all MSM aged 26 years (maximum age for HPV vaccination eligibility) in 2016, who answered the questionnaire in 2019 , to be included in the analysis.

The questionnaire gathered information on selfreported vaccination status for HPV, hepatitis $A$ and hepatitis B ('yes' and among those answering 'yes': 'one dose', 'two or more doses' or 'I don't know' options) and on the screening uptake for sexually transmitted infections. Information gathered on potential determinants of vaccination included: socio-demographic characteristics (origin, residence, financial status and education level); lifestyle such as circle of friends, number of sexual partners, attendance to saunas, bars, backrooms, outdoor meeting places or sex parties, use of web applications to date MSM; use of HIV prevention methods, namely condoms or biomedical HIV-related preventive measures (e.g. HIV pre-exposure prophylaxis (PrEP), treatment as prevention (TasP), treatment post-exposure (TPE)); and health determinants including perception of risk of being infected with an STI; uptake of screening for STI (syphilis, chlamydia, gonorrhoea, condyloma, hepatitis B and hepatitis C), and STI diagnoses.

\section{Statistical analysis}

The questionnaire did not have the option to skip any of the questions; therefore, we did not have missing data. For numeric variables, we calculated means (and standard deviations) or medians (and ranges). We calculated the HPV vaccination coverage for at least one dose or for at least two doses, using as denominator those who answered 'yes', 'no' or 'unknown' to the relevant question. In this paper, we report the results from this analysis. The results of the sensitivity analysis where we excluded the unknown vaccination status from the denominator are in the Supplement.

To identify factors associated with HPV vaccination (at least one dose), we calculated prevalence ratios (PR) and $95 \%$ confidence intervals $(95 \% \mathrm{Cl})$. To calculate adjusted $\mathrm{PR}$, we used Poisson regression. We included in the initial regression models all factors with a $p$ value $<0.2$ in the univariable analysis and those that could have been relevant for vaccination coverage based on the literature. We removed variables one at a time using the Wald test or the Akaike information criterium.

\section{Ethical statement}

The study follows the ethical guidelines of the 1975 Helsinki Declaration. By clicking on a link or banner, the participant was directed to the survey site, which 
TABLE 1A

Description of the total MSM population, MSM vaccinated for HPV (any dose) and MSM not vaccinated (or with unknown vaccination status), aged $18-28$ years, France, $2019(\mathrm{n}=9,469)$

\begin{tabular}{|c|c|c|c|c|c|c|c|}
\hline \multirow[t]{2}{*}{ Characteristics } & \multicolumn{2}{|c|}{$\begin{array}{l}\text { All MSM } \\
(n=9,469)\end{array}$} & \multicolumn{2}{|c|}{$\begin{array}{l}\text { HPV-vaccinated MSM } \\
\qquad(n=1,420)\end{array}$} & \multicolumn{2}{|c|}{$\begin{array}{l}\text { MSM not vaccinated (or status } \\
\text { unknown) } \\
(\mathrm{n}=8,049)\end{array}$} & \multirow[t]{2}{*}{$\mathrm{p}$ value } \\
\hline & $\mathrm{n}$ & $\%$ & $n$ & $\%$ & $\mathrm{n}$ & $\%$ & \\
\hline \multicolumn{8}{|l|}{ Age group (years) } \\
\hline $18-19$ & 1,686 & 17.8 & 276 & 19.4 & 1,410 & 17.5 & \multirow{3}{*}{0.040} \\
\hline $20-24$ & 4,974 & 52.5 & 759 & 53.5 & 4,215 & 52.4 & \\
\hline $25-28$ & 2,809 & 29.7 & 385 & 27.1 & 2,424 & 30.1 & \\
\hline \multicolumn{8}{|l|}{ Residence area (region) } \\
\hline Île-de-France & 2,116 & 22.4 & 315 & 22.2 & 1,801 & 22.4 & \multirow{3}{*}{ NS } \\
\hline Overseas French departments & 277 & 2.90 & 39 & 2.75 & 238 & 2.96 & \\
\hline Other regions & 7,076 & 74.7 & 1,066 & 75.1 & 6,010 & 74.7 & \\
\hline \multicolumn{8}{|l|}{ Commune of residence } \\
\hline Rural («2,000 inhabitants) & 1,368 & 14.5 & 231 & 16.3 & 1,137 & 14.1 & \multirow{2}{*}{0.034} \\
\hline Urban & 8,101 & 85.6 & 1,189 & 83.7 & 6,912 & 85.9 & \\
\hline \multicolumn{8}{|l|}{ Origin (region) } \\
\hline Mainland France & 8,606 & 90.9 & 1,277 & 89.9 & 7,329 & 91.1 & \multirow{3}{*}{ NS } \\
\hline Overseas French departments & 366 & 3.90 & 53 & 3.73 & 313 & 3.89 & \\
\hline Other countries & 497 & $5 \cdot 30$ & 90 & 6.34 & 407 & 5.06 & \\
\hline \multicolumn{8}{|l|}{ Financial status } \\
\hline Comfortable, getting by & 4,859 & 51.3 & 746 & 52.5 & 4,113 & 51.1 & \multirow{2}{*}{ NS } \\
\hline Struggling, soon to be in debt & 4,610 & 48.7 & 674 & 47.5 & 3,936 & 48.9 & \\
\hline \multicolumn{8}{|l|}{ Education level } \\
\hline College, baccalaureate & 2,871 & 30.3 & 476 & 33.5 & 2,395 & 29.8 & \multirow{2}{*}{0.004} \\
\hline Higher education (university, Master, PhD) & 6,598 & 69.7 & 944 & 66.5 & 5,654 & 70.2 & \\
\hline \multicolumn{8}{|l|}{ Self-reported sexual orientation } \\
\hline Homosexual & 6,883 & 72.7 & 1,040 & 73.2 & 5,843 & 72.6 & \multirow{2}{*}{ NS } \\
\hline Bisexual or heterosexual or refused to answer & 2,586 & 27.3 & 380 & 26.8 & 2,206 & 27.4 & \\
\hline \multicolumn{8}{|l|}{ Attendance of saunas, bars, backrooms } \\
\hline No & 5,140 & 54.3 & 747 & 52.6 & 4,393 & 54.6 & \multirow{2}{*}{ NS } \\
\hline Yes & 4,329 & $45 \cdot 7$ & 673 & 47.4 & 3,656 & 45.4 & \\
\hline \multicolumn{8}{|c|}{ Attendance of outdoor meeting places (cruising areas) } \\
\hline No & 7,868 & 83.1 & 1,143 & 80.5 & 6,725 & 83.6 & 0.005 \\
\hline Yes & 1,601 & 16.9 & 277 & 19.5 & 1,324 & 16.5 & 0.005 \\
\hline Attendance of sex parties & & & & & & & \\
\hline No & 8,667 & 91.5 & 1,245 & 87.7 & 7,422 & 92.2 & $<10^{-3}$ \\
\hline Yes & 802 & 8.47 & 175 & 12.3 & 627 & 7.79 & 10 \\
\hline Use of Internet sites or web applications for meet & USM & & & & & & \\
\hline No & 2,365 & 25.0 & 345 & 24.3 & 2,020 & 25.1 & NS \\
\hline Yes & 7,104 & 75.0 & 1,075 & 75.7 & 6,029 & 74.9 & NSS \\
\hline Circle of friends & & & & & & & \\
\hline Mainly homosexual & 450 & 4.75 & 89 & 6.27 & 361 & 4.49 & 0.004 \\
\hline Homosexual and others (bisexual, heterosexual) & 9,019 & 95.3 & 1,331 & 93.7 & 7,688 & 95.5 & \\
\hline Vaccination uptake (self-declared) & & & & & & & \\
\hline Hepatitis A & & & & & & & \\
\hline Not vaccinated & 1,971 & 20.8 & 82 & 5.77 & 1,889 & 23.5 & \\
\hline Vaccinated, any dose & 4,050 & 42.8 & 1,274 & 89.7 & 2,776 & 34.5 & $<10^{-3}$ \\
\hline Unknown status & 3,448 & 36.4 & 64 & 4.51 & 3,384 & 42.0 & \\
\hline
\end{tabular}

MSM: men who have sex with men; TasP: treatment as prevention; PrEP: pre-exposure prophylaxis; STI: sexually transmitted infection; TPE: treatment post-exposure. NS: not significant.

a Scale: $0-7=$ low $/$ moderate; $8-10=$ high. 
Description of the total MSM population, MSM vaccinated for HPV (any dose) and MSM not vaccinated (or with unknown vaccination status), aged 18-28 years, France, $2019(\mathrm{n}=9,469)$

\begin{tabular}{|c|c|c|c|c|c|c|c|}
\hline \multirow[t]{2}{*}{ Characteristics } & \multicolumn{2}{|c|}{$\begin{array}{l}\text { All MSM } \\
(n=9,469)\end{array}$} & \multicolumn{2}{|c|}{$\begin{array}{l}\text { HPV-vaccinated MSM } \\
\qquad(n=1,420)\end{array}$} & \multicolumn{2}{|c|}{$\begin{array}{l}\text { MSM not vaccinated (or status } \\
\text { unknown) } \\
(n=8,049)\end{array}$} & \multirow[t]{2}{*}{$\mathrm{p}$ value } \\
\hline & $\mathrm{n}$ & $\%$ & $\mathrm{n}$ & $\%$ & $\mathrm{n}$ & $\%$ & \\
\hline Not vaccinated & 1,533 & 16.2 & 55 & 3.87 & 1,478 & 18.4 & \multirow{3}{*}{$<10^{-3}$} \\
\hline Vaccinated, any dose & 5,102 & 53.9 & 1,328 & 93.5 & 3,774 & 46.9 & \\
\hline Unknown status & 2,834 & 29.9 & 37 & 2.61 & 2,797 & 34.8 & \\
\hline \multicolumn{8}{|c|}{ Screening uptake for any STI in the last 12 months (including HIV) } \\
\hline Not screened & 3,973 & 42.0 & 473 & 33.3 & 3,500 & 43.5 & \multirow{2}{*}{$<10^{-3}$} \\
\hline Screened & 5,496 & 58.0 & 947 & 66.7 & 4,549 & 56.5 & \\
\hline \multicolumn{8}{|c|}{ Result of HPV or condyloma screening in the last 12 months } \\
\hline Not screened or negative & 9,249 & 97.7 & 1,372 & 96.6 & 7,877 & 97.9 & \multirow{2}{*}{0.004} \\
\hline Positive & 220 & 2.32 & 48 & 3.38 & 172 & 2.14 & \\
\hline \multicolumn{8}{|l|}{ Result of any of the screenings performed } \\
\hline Not screened or negative & 8,543 & 90.2 & 1,206 & 84.9 & 7,337 & 91.15 & \multirow{2}{*}{$<10^{-3}$} \\
\hline Positive & 926 & 9.80 & 214 & 15.1 & 712 & 8.85 & \\
\hline \multicolumn{8}{|l|}{ HIV status and use of PrEp } \\
\hline HIV-positive & 81 & 0.90 & 23 & 1.62 & 58 & 0.72 & \multirow{4}{*}{0,004} \\
\hline HIV-negative and PrEP user & 238 & 2.50 & 87 & 6.13 & 151 & 1.88 & \\
\hline HIV-negative and not PrEp user & 6,258 & 66.1 & 940 & 66.2 & 5,318 & 66.1 & \\
\hline Unknown HIV status & 2,892 & 30.5 & 370 & 26.1 & 2,522 & 31.3 & \\
\hline \multicolumn{8}{|c|}{ Prevention methods used during the last sexual intercourse } \\
\hline No prevention methods & 4,887 & 51.6 & 669 & 47.1 & 4,218 & 52.4 & \multirow{4}{*}{$<10^{-3}$} \\
\hline Condom use & 3,227 & 34.1 & 494 & 34.8 & 2,733 & 34.0 & \\
\hline Biomedical prevention (TasP, PrEP, TPE) & 404 & 4.27 & 121 & 8.52 & 283 & 3.52 & \\
\hline No sexual intercourse or practicing masturbation & 951 & 10.0 & 136 & 9.58 & 815 & 10.1 & \\
\hline \multicolumn{8}{|c|}{ Perception of risk of contracting STI other than HIV in the last 6 months } \\
\hline Low/moderate ${ }^{a}$ & 7,450 & 78.7 & 1,122 & 79.0 & 6,328 & 78.6 & \multirow{3}{*}{0.028} \\
\hline High $^{\mathrm{a}}$ & 562 & 5.90 & 102 & 7.18 & 460 & 5.71 & \\
\hline No sexual partner in the last 6 months & 1,457 & 15.4 & 196 & 13.8 & 1,261 & 15.7 & \\
\hline \multicolumn{8}{|c|}{ Number of occasional male sexual partners in the last 6 months } \\
\hline $0-1$ & 4,746 & 50.1 & 662 & 46.6 & 4,084 & 50.7 & \multirow{2}{*}{0.004} \\
\hline 2 or more & 4,723 & 49.9 & 758 & 53.4 & 3,965 & 49.3 & \\
\hline
\end{tabular}

MSM: men who have sex with men; TasP: treatment as prevention; PrEP: pre-exposure prophylaxis; STI: sexually transmitted infection; TPE: treatment post-exposure. NS: not significant.

a Scale: $0-7=$ low $/$ moderate; $8-10=$ high.

contained information about the aims and contents of the survey, terms of participation and data privacy. By clicking on a button containing the text "I have read and understood the information above", the participant provided informed consent and was directed to the online questionnaire. The questionnaire was anonymous and self-administered and no IP addresses were collected. Santé Publique France review board approved the consent procedures on 20 March 2017 (DDPS-09).

\section{Results}

Of the 24,308 respondents, 10,553 were between 18 and 28 years-old and within this population, 9,469 (median age: 23 years) met the inclusion criteria and were included in the analysis. Participants were from various regions and $22 \%$ lived in île-de-France (Table
1). Among all participants, $73 \%(n=6,883)$ defined themselves as homosexual and the remaining as bisexual, heterosexual or refused to answer; $70 \%(n=6,598)$ had high education (Table 1 ).

Among the MSM, $15 \%$ (95\% Cl: 14-16; $n=1,420)$ reported being vaccinated against HPV, any dose, and $4.3 \%(95 \% \mathrm{Cl}: 3.9-4.7 ; \mathrm{n}=406)$ reported being vaccinated with two doses or more.

Of the MSM who reported being vaccinated with at least one HPV dose, 90\% $(n=1,274)$ reported having been vaccinated for hepatitis $A$ and $94 \%(n=1,328)$ for hepatitis $B ; 67 \%(n=947)$ reported having done at least one screening for STI including HIV; $3.4 \%(n=48)$ reported a previous HPV infection or condyloma and $15 \%(n=214)$ a positive diagnosis to any of the STI 
screenings performed in the last 12 months (other than HPV or condyloma, Tables 1 and 2). In terms of HIV, $1.6 \%$ $(n=23)$ reported to be HIV-positive, 66\% $(n=940)$ were HIV-negative and did not use PrEP and 6.1\% $(n=87)$ were HIV-negative and PrEP users; 47\% $(n=669)$ of HPV-vaccinated MSM did not use any HIV prevention methods during their last anal sexual intercourse, 35\% $(n=494)$ used condoms exclusively and $8.5 \%(n=121)$ reported having used biomedical prevention methods (TasP, PrEP or TPE). The majority of the respondents also had a low or moderate perception of being at risk of contracting STI other than HIV $(79 \% ; n=1,122)$, during the preceding 6 months and a majority $(n=1,224)$ had one or more sexual partners.

In the multivariable analysis, HPV vaccination coverage was significantly higher among MSM younger than 24 years (age $18-19$ years: $P R=1.4 ; 95 \% \mathrm{Cl}: 1.2-1.4$; and age $20-24$ years: $P R=1.3 ; 95 \% \mathrm{Cl}: 1.1-1.4)$, among those with an education level below university degree $(P R=1.1 ; 95 \% \mathrm{Cl}: 1.1-1.3)$, those living in rural areas $(P R=1.2 ; 95 \% \mathrm{Cl}: 1.1-1.4)$ and those attending sex parties ( $P R=1.1 ; 95 \% \mathrm{Cl}: 1.0-1.3$ ) (Table 2). The MSM who had benefited from biomedical HIV prevention methods during the last anal intercourse $(P R=1.3$; $95 \% \mathrm{Cl}: 1.1-1.5)$, those that declared having at least one STI diagnosis in the previous 12 months $(P R=1.2$; $95 \% \mathrm{Cl}: 1.1-1.4)$ and those vaccinated for hepatitis $A$ or $\mathrm{B}(\mathrm{PR}=4.6 ; 95 \% \mathrm{Cl}: 3.6-5.8$ and $\mathrm{PR}=3.4 ; 95 \% \mathrm{Cl}$ : $2.5-4.4$, respectively) were also more likely to be vaccinated for HPV than others (Table 2). We did not observe collinearity or interaction between age and education or age and any other variable (data not shown).

We conducted the above analysis considering two doses of HPV vaccination. However, the number of observations was very small and not sufficiently powered for a meaningful analysis.

Results from the sensitivity analysis (see Supplement), where we excluded the unknown vaccination status from the denominator, were consistent with the main results as presented above, namely associations between higher HPV vaccination and younger age, residence in rural area, lower education status and reporting other vaccinations such as hepatitis $A$ and hepatitis $B$. Living in regions other than île-de-France was positively associated with HPV vaccination, possibly reflecting residence in rural areas. The sensitivity analysis diverged from the presented analysis for other factors such as association with the use of biomedical HIV prevention methods and attendance at sex parties as these variables were significant in the univariable analysis, but did not remain significant in the multivariable analysis.

\section{Discussion}

Our analysis indicated an HPV vaccination coverage (any dose) of $15 \%$ among all MSM aged 18-28 years, indicating an unsatisfactory level of vaccination in this high-risk group. A similar HPV coverage (any dose of
$18 \%$ among MSM was reported in an online survey performed in 2018 in France [21]. HPV vaccination of girls has also been reported to be as low as $24 \%$ for two doses in France [22]. This level of immunity is not high enough to offer protection to boys, and MSM do not directly benefit from vaccination of girls through herd immunity. HPV vaccination for boys aged 11-14 years (with a catch-up vaccination up to age 19 years) will be implemented in France in 2021 [16]. However, even with universal vaccination, protection from HPV cancers of future MSM populations will take more than a decade to take effect, indicating that MSM remain highly vulnerable to HPV-related diseases. This low HPV coverage in MSM in France highlights the need to increase awareness of the impact of HPV infections specifically in MSM and the urgency to invest resources to improve vaccination uptake in this vulnerable population.

In this study, we also observed that only $4.3 \%$ among all respondents reported having received two doses or more of HPV vaccine. When given at young age, two doses of HPV vaccine are recommended; if vaccination is started at age 15 years or later, a three-dose regime should be followed to ensure optimal effectiveness [23]. Our results raise concerns about the impact of this vaccination in MSM in the long term, considering the very low level of uptake of the second dose. In another study among MSM in France, the vaccine uptake for three doses was estimated at 3.4\%, which is consistent with our results [21]. Similar unsatisfactory HPV vaccination coverage for two doses has been reported in adolescent girls in France, with $24 \%$ coverage in 2018 [22]. Further studies are needed to explore access to subsequent doses of vaccination following the first one.

Information about HPV vaccination coverage in the MSM population in other countries is limited, either because vaccination targeting this group has only recently begun, e.g. in Canada [24] or Ireland [25], or because coverage has been calculated in specific MSM groups, for instance MSM accessing sexual health clinics for other medical issues, such as in the United Kingdom (UK) [26]. Some data are available from the United States (US), where HPV vaccination among MSM attending gay venues was reported at a level similar to our results (17\%) [27].

Our findings indicate that higher HPV vaccination in MSM was associated with younger age. Association with younger age has already been documented in previous studies in the US [27-29]. However, we should take into consideration that convenience sampling methods such as ERAS are known to induce participation bias linked to age [30-32]. Participating in such surveys involves spending time at gay cruising or dating websites, and younger age groups, more sexually active than older groups, are likely to spend more time on such websites. Younger participants are possibly also the most self-assured about their own homosexuality, probably more informed about preventive health 
TABLE 2A

Characteristics of MSM who declared being vaccinated for HPV (any dose) and associated factors age group 18-28 years, France, $2019(\mathrm{n}=1,420)$

\begin{tabular}{|c|c|c|c|c|c|c|c|c|c|}
\hline \multirow{2}{*}{ Characteristics } & \multicolumn{3}{|c|}{ HPV-vaccinated MSM } & \multicolumn{3}{|c|}{ Univariable analysis } & \multicolumn{3}{|c|}{ Multivariable analysis } \\
\hline & $\mathrm{n}$ & $\%$ & $95 \% \mathrm{Cl}$ & PR & $95 \% \mathrm{Cl}$ & $\mathrm{p}$ & PR & $95 \% \mathrm{Cl}$ & $\mathrm{p}$ \\
\hline \multicolumn{10}{|l|}{ Age group (years) } \\
\hline $18-19$ & 276 & 16.4 & $14.7-18.2$ & 1.19 & $1.04-1.38$ & 0.014 & 1.43 & $1.24-1.64$ & $<0.001$ \\
\hline $20-24$ & 759 & 15.3 & $14.3-16.3$ & 1.11 & $0.99-1.25$ & 0.064 & 1.25 & $1.13-1.39$ & $<0.001$ \\
\hline $25-28$ & 385 & 13.7 & $12.5-15.0$ & \multicolumn{3}{|c|}{ Ref } & \multicolumn{3}{|c|}{ Ref } \\
\hline \multicolumn{10}{|l|}{ Residence area (region) } \\
\hline Île-de-France & 315 & 14.9 & $13.4-16.5$ & \multicolumn{3}{|c|}{ Ref } & & & \\
\hline Overseas French departments & 39 & 14.1 & $10.5-18.7$ & 0.95 & $0.70-1.29$ & 0.723 & & & \\
\hline Other regions & 1,066 & 15.0 & $14.3-15.9$ & 1.01 & $0.90-1.14$ & 0.840 & & & \\
\hline \multicolumn{10}{|l|}{ Commune of residence } \\
\hline Rural («2,000 inhabitants) & 231 & 16.9 & $15.0-19.0$ & 1.15 & $1.01-1.31$ & 0.033 & 1.21 & $1.08-1.36$ & 0.001 \\
\hline Urban & 1,189 & 14.7 & $13.9-15.5$ & \multicolumn{3}{|c|}{ Ref } & \multicolumn{3}{|c|}{ Ref } \\
\hline \multicolumn{10}{|l|}{ Origin (region) } \\
\hline France metropolitan & 1,277 & 14.8 & $14.1-15.6$ & \multicolumn{3}{|c|}{ Ref } & & & \\
\hline Overseas French departments & 53 & 14.5 & $11.2-18.5$ & 0.98 & $0.76-1.26$ & 0.851 & & & \\
\hline Other countries & 90 & 18.1 & $15.0-21.7$ & 1.22 & $1.01-1.48$ & 0.044 & & & \\
\hline \multicolumn{10}{|l|}{ Financial status } \\
\hline Comfortable, getting by & 746 & 15.4 & $14.4-16.4$ & 1.05 & $0.95-1.16$ & 0.318 & & & \\
\hline Struggling, soon to be in debt & 674 & 14.6 & $13.6-15.7$ & \multicolumn{3}{|c|}{ Ref } & & & \\
\hline \multicolumn{10}{|l|}{ Education level } \\
\hline College, baccalaureate & 476 & 16.6 & $15.3-18.0$ & 1.16 & $1.05-1.28$ & 0.004 & 1.12 & $1.08-1.32$ & $<0.001$ \\
\hline Higher education (university, Master, PhD) & 944 & 14.3 & $13.5-15.1$ & \multicolumn{3}{|c|}{ Ref } & \multicolumn{3}{|c|}{ Ref } \\
\hline \multicolumn{10}{|l|}{ Self-reported sexual orientation } \\
\hline Homosexual & 1,040 & 15.1 & $14.3-16.0$ & 1.03 & $0.92-1.15$ & 0.615 & & & \\
\hline Bisexual or heterosexual or refused to answer & 380 & 14.7 & $13.4-16.1$ & \multicolumn{3}{|c|}{ Ref } & & & \\
\hline \multicolumn{10}{|l|}{ Attendance of saunas, bars, backrooms } \\
\hline No & 747 & 14.5 & $13.6-15.5$ & \multicolumn{3}{|c|}{ Ref } & & & \\
\hline Yes & 673 & 15.6 & $14.5-16.7$ & 1.07 & $0.97-1.18$ & 0.169 & & & \\
\hline Attendance of outdoor meeting places (cruising a & & & & & & & & & \\
\hline No & 1,143 & 14.5 & $13.8-15 \cdot 3$ & & Ref & & & & \\
\hline Yes & 277 & 17.3 & $15.5-19.2$ & 1.19 & $1.06-1.34$ & 0.004 & & & \\
\hline Attendance of sex parties & & & & & & & & & \\
\hline No & 1,245 & $14 \cdot 4$ & $13.6-15.1$ & & Ref & & & Ref & \\
\hline Yes & 175 & 21.8 & $19.1-24.8$ & 1.52 & $1.32-1.75$ & $<0.001$ & 1.12 & $1.03-1.33$ & 0.019 \\
\hline Use of Internet sites or web applications for meet & g MSM & & & & & & & & \\
\hline No & 345 & 14.6 & $13.2-16.1$ & & Ref & & & & \\
\hline Yes & 1,075 & 15.1 & $14.3-16.0$ & 1.04 & $0.93-1.16$ & 0.521 & & & \\
\hline Circle of friends & & & & & & & & & \\
\hline Mainly homosexual & 89 & 19.8 & $16.4-23.7$ & 1.34 & $1.11-1.62$ & 0.003 & & & \\
\hline Homosexual and others (bisexual, heterosexual) & 1,331 & 14.8 & $14.0-15 \cdot 5$ & & Ref & & & & \\
\hline Vaccination uptake (self-declared) & & & & & & & & & \\
\hline Hepatitis A & & & & & & & & & \\
\hline
\end{tabular}

Cl: confidence interval; MSM: men who have sex with men; TasP: treatment as prevention; PR: prevalence ratio; PrEP: pre-exposure prophylaxis; Ref: reference value; STI: sexually transmitted infection; TPE: treatment post-exposure.

a Scale: $0-7=$ low/moderate; $8-10=$ high.

Prevalences are shown as row percentages (totals in Table 1). For the multivariable analysis, we show only prevalence ratios related to variables included in the multivariable model and remaining significant in the final accepted model. Significant values are shown in bold. 


\section{TABLE 2B}

Characteristics of MSM who declared being vaccinated for HPV (any dose) and associated factors age group 18-28 years, France, $2019(\mathrm{n}=1,420)$

\begin{tabular}{|c|c|c|c|c|c|c|c|c|c|}
\hline \multirow{2}{*}{ Characteristics } & \multicolumn{3}{|c|}{ HPV-vaccinated MSM } & \multicolumn{3}{|c|}{ Univariable analysis } & \multicolumn{3}{|c|}{ Multivariable analysis } \\
\hline & $\mathrm{n}$ & $\%$ & $95 \% \mathrm{Cl}$ & PR & $95 \% \mathrm{Cl}$ & $\mathrm{p}$ & PR & $95 \% \mathrm{Cl}$ & $\mathrm{p}$ \\
\hline Not vaccinated & 82 & 4.2 & $3.4-5.1$ & \multicolumn{3}{|c|}{ Ref } & \multicolumn{3}{|c|}{ Ref } \\
\hline Vaccinated, any dose & 1,274 & 31.5 & $30.0-32.9$ & 7.56 & $6.09-9.39$ & $<0.001$ & 4.56 & $3.63-5.81$ & $<0.001$ \\
\hline Unknown status & 64 & 1.9 & $1.5-2.4$ & 0.45 & $0.32-0.62$ & $<0.001$ & 0.71 & $0.49-1.03$ & 0.069 \\
\hline \multicolumn{10}{|l|}{ Hepatitis B } \\
\hline Not vaccinated & 55 & 3.6 & $2.8-4.6$ & \multicolumn{3}{|c|}{ Ref } & \multicolumn{3}{|c|}{ Ref } \\
\hline Vaccinated, any dose & 1,328 & 26.0 & $24.8-27.3$ & 7.26 & $5.57-9.44$ & $<0.001$ & 3.35 & $2.53-4.44$ & $<0.001$ \\
\hline Unknown status & 37 & 1.3 & $0.9-1.8$ & 0.36 & $0.24-0.55$ & $<0.001$ & 0.61 & $0.38-0.98$ & 0.041 \\
\hline \multicolumn{10}{|c|}{ Screening uptake for any STI in the last 12 months (including HIV) } \\
\hline Not screened & 473 & 11.9 & $10.9-12.9$ & \multicolumn{3}{|c|}{ Ref } & & & \\
\hline Screened & 947 & 17.2 & $16.3-18.3$ & 1.45 & $1.31-1.60$ & $<0.001$ & & & \\
\hline \multicolumn{10}{|c|}{ Result of HPV or condyloma screening in the last 12 months } \\
\hline Not screened or negative & 1,372 & 14.8 & $14.1-15.6$ & \multicolumn{3}{|c|}{ Ref } & & & \\
\hline Positive & 48 & 21.8 & $16.9-27.8$ & 1.47 & $1.14-1.90$ & 0.003 & & & \\
\hline \multicolumn{10}{|l|}{ Result of any of the screenings performed } \\
\hline Not screened or negative & 1,206 & 14.1 & $13.4-14.9$ & \multicolumn{3}{|c|}{ Ref } & \multicolumn{3}{|c|}{ Ref } \\
\hline Positive & 214 & 23.1 & $20.5-25.9$ & 1.64 & $1.44-1.86$ & $<0.001$ & 1.22 & $1.08-1.38$ & 0.002 \\
\hline \multicolumn{10}{|l|}{ HIV status and use of PrEp } \\
\hline HIV-positive & 23 & 28.4 & $19.7-39.1$ & 1.89 & $1.33-2.68$ & $<0.001$ & & & \\
\hline HIV-negative and PrEP user & 87 & 36.6 & $30.7-42.9$ & 2.43 & $2.04-2.91$ & $<0.001$ & & & \\
\hline HIV-negative and not PrEp user & 940 & 15.0 & $14.2-15.9$ & \multicolumn{3}{|c|}{ Ref } & & & \\
\hline Unknown & 370 & 12.8 & $11.6-14.1$ & 0.85 & $0.76-0.95$ & 0.005 & & & \\
\hline \multicolumn{10}{|c|}{ Prevention methods used during the last sexual intercourse } \\
\hline No prevention methods & 669 & 13.7 & $12.8-14 \cdot 7$ & \multicolumn{3}{|c|}{ Ref } & \multicolumn{3}{|c|}{ Ref } \\
\hline Condom use & 494 & $15 \cdot 3$ & $14.1-16.6$ & 1.12 & $1.00-1.25$ & 0.041 & 1.03 & $0.93-1.13$ & 0.562 \\
\hline Biomedical prevention (TasP, PrEP, TPE) & 121 & 30.0 & $25.7-34.6$ & 2.19 & $1.86-2.58$ & $<0.001$ & 1.31 & $1.12-1.54$ & 0.001 \\
\hline $\begin{array}{l}\text { No sexual intercourse or practicing } \\
\text { masturbation }\end{array}$ & 136 & $14 \cdot 3$ & $12.2-16.7$ & 1.04 & $0.88-1.24$ & 0.616 & 1.05 & $0.90-1.22$ & 0.538 \\
\hline \multicolumn{10}{|c|}{ Perception of risk of contracting STI other than HIV in the last 6 months } \\
\hline Low/moderate $^{a}$ & 1,122 & 15.1 & $14.3-15.9$ & \multicolumn{3}{|c|}{ Ref } & & & \\
\hline $\mathrm{High}^{\mathrm{a}}$ & 102 & 18.2 & $15.2-21.6$ & 1.21 & $1.00-1.45$ & 0.046 & & & \\
\hline No sexual partners in the last 6 months & 196 & 13.5 & $11.8-15.3$ & 0.89 & $0.78-1.03$ & 0.116 & & & \\
\hline \multicolumn{10}{|c|}{ Number of occasional male sexual partners in the last 6 months } \\
\hline $0-1$ & 662 & 14.0 & $13.0-15.0$ & \multicolumn{3}{|c|}{ Ref } & & & \\
\hline 2 or more & 758 & 16.1 & $15.0-17.1$ & 1.15 & $1.05-1.27$ & 0.004 & & & \\
\hline
\end{tabular}

$\mathrm{Cl}$ : confidence interval; MSM: men who have sex with men; TasP: treatment as prevention; PR: prevalence ratio; PrEP: pre-exposure prophylaxis; Ref: reference value; STI: sexually transmitted infection; TPE: treatment post-exposure.

a Scale: $0-7=$ low/moderate; $8-10=$ high.

Prevalences are shown as row percentages (totals in Table 1). For the multivariable analysis, we show only prevalence ratios related to variables included in the multivariable model and remaining significant in the final accepted model. Significant values are shown in bold. 
related to sexual practices and more keen to answer surveys on sexual health.

We saw that higher HPV vaccination in MSM was positively associated with lower education level, a result in contrast to what has been observed for instance in the US [33]. In France, the association between educational level and adhesion to vaccination varies according to studies and vaccines. In a 2016 study on vaccine perception in France [34], a greater proportion of vaccine positivity was reported among parents with a lower educational level. Another study on determinants of HPV vaccination reported a lower uptake among girls who had parents with higher educational level, but the opposite was observed among women aged 15-25 years [35]. In our analysis, it is unlikely that the apparent association between higher vaccination and lower education level was the confounding effect of age, as we adjusted for age.

Similarly to our results, higher vaccine uptake in MSM living in rural settings was also reported in a 2016 pilot study in the UK, but no explanations for this finding were provided [26]. Conversely, results in the US indicated higher vaccine uptake in urban settings $[28,36]$. We cannot explain our findings in France, especially considering that the CeGIDD are mostly located in hospitals in urban areas and these centres are where MSM receive medical support related to sexual health, including recommended vaccinations.

Diagnosis of any STI in the last 12 months and vaccinations for hepatitis $A$ and $B$ (recommended to MSM in France [37,38]) were positively associated with HPV vaccination. This association may reflect a contact with sexual healthcare personnel who recommend a package of interventions, including HPV vaccination, for MSM following disclosure of their homosexuality. This hypothesis is corroborated by a 2016 French study reporting that general practitioners advised for example vaccination against hepatitis A virus, to MSM who disclosed their sexual orientation [39]. These findings concur with the higher vaccination coverage in MSM using HIV-preventive biomedical interventions such as TasP, PrEP or TPE in our study. A positive association between HPV vaccination and implementation of medical preventive measures or provision of recommendations targeting MSM was also reported in Australia [40]. However, our data do not allow to conclude whether this association reflects a specific profile of certain MSM more prone to adopt various prevention measures regarding risks attached to their sexual practices, the linked offer of vaccination with other prevention measures by specialised heath structures offering care to MSM or a combination of both. Of note, in France, PrEP is provided free of charge and the first consultation before PrEP prescription implies a medical check-up that should include a recommendation on vaccinations (hepatitis A, hepatitis B and HPV) [41].
We also identified a positive association between attendance at sex parties and HPV vaccination, although in the sensitivity analysis, this association did not remain significant. Attendance at sex parties where group sex can occur has previously been associated with higher risk of STI and with use of PrEP in HIV-negative MSM [42]. MSM engaging in risky sexual behaviours may be more proactive in accessing sexual health clinics and adopting sexual health-related MSM-specific preventive measures, including HPV vaccination. On the other hand, men who have not yet declared their homosexuality or assumed their sexual orientation are potentially unaware of HPV vaccination, probably because they are not linked to the MSM community; however, the risk of being infected with HPV may increase once they have decided and accepted their sexual orientation.

Based on these results it would be important to identify ways to reach adolescent males after sexual debut and ensure that HPV prevention measures are known and adopted. It should be considered that while we cannot rule out any bias caused by the classification of men with unknown status as unvaccinated in the main analysis, these discrepancies between the main and the sensitivity analyses may be due to the high number of unknown answers and the consequent elimination of more than half of the available observations in the sensitivity analysis, which may have decreased the power and therefore the possibility to obtain significant associations, apart from the strongest.

The main strength of our study was that we used a large dataset with a diversified the MSM population in terms of socio-demographic characteristics.

Our study had some limitations. Firstly, men assertive about their homosexuality, more interested in sexual health prevention or affected by STI may have been more likely to complete the online questionnaire, suggesting that participants might not be representative of the whole MSM population and introducing a potential selection bias [32]. This bias could have led to an overestimated vaccination uptake compared with what we could have observed if even those not affected by STI or less interested had participated; therefore the actual vaccine coverage may be even lower than estimated in our data. However, the use of different types of platforms to advertise this survey may have helped recruit individuals with different background, interests, health status, lifestyle and geographical setting and may have limited this potential bias. Secondly, vaccination status and the number of vaccination doses were self-reported. Self-reported vaccination status may be influenced by recall bias, especially regarding the number of doses received, leading to a potential underestimation of the vaccine uptake for at least two doses.

\section{Conclusions}

The low HPV vaccination coverage among MSM raises concerns about the possibility of decreasing the burden 
of HPV-related lesions and cancers in this population in France. Lower uptake was associated with older age, higher education level and living in urban areas. Higher vaccine uptake was observed among MSM benefitting from other vaccinations and biomedical preventive methods against HIV. It is essential to continue the vaccination programme targeting MSM and to invest further resources to improve awareness among MSM of the risk of HPV-related diseases and the importance of vaccination. In addition, it would be useful to establish a surveillance strategy to periodically estimate vaccination uptake in this population and to assess the impact of this vaccination approach by monitoring the prevalence of HPV infections in the MSM population. Improvement of HPV vaccination coverage in MSM will eventually contribute to the national HPV vaccination objectives.

\section{Acknowledgements}

We thank all the participants to the study and the National Agency for AIDS Research and Viral hepatitis for implementing this survey.

Funding: Rapport au Sexe study was supported by the French National Agency for research on AIDS and Viral hepatitis (ANRS)

\section{Conflict of interest}

None declared.

\section{Authors' contributions}

AV designed the study; LD cleaned the data; GO performed the analysis; $L D, K D, A V, A S B$, contributed to the data interpretation; $\mathrm{GO}$ conceptualised and drafted the manuscript; $A V, A S B, K D, D L B$ critically reviewed the paper, and all the authors finalised the manuscript. The views expressed in this document by the authors do not necessarily represent the opinion of their affiliated institutions.

\section{References}

1. de Martel C, Plummer M, Vignat J, Franceschi S. Worldwide burden of cancer attributable to HPV by site, country and HPV type. Int J Cancer. 2017;141(4):664-70. https://doi. org/10.1002/ijc.30716 PMID: 28369882

2. Reusser NM, Downing C, Guidry J, Tyring SK. HPV carcinomas in immunocompromised patients. I Clin Med. 2015;4(2):260-81. https://doi.org/10.3390/jcm4020260 PMID: 26239127

3. Machalek DA, Poynten M, Jin F, Fairley CK, Farnsworth A, Garland SM, et al. Anal human papillomavirus infection and associated neoplastic lesions in men who have sex with men: a systematic review and meta-analysis. Lancet Oncol. 2012;13(5):487-500. https://doi.org/10.1016/S14702045(12)70080-3 PMID: 22445259

4. Piketty C, Selinger-Leneman H, Bouvier A-M, Belot A, MaryKrause M, Duvivier C, et al. Incidence of HIV-related anal cancer remains increased despite long-term combined antiretroviral treatment: results from the french hospital database on HIV. J Clin Oncol. 2012;30(35):4360-6. https:// doi.org/10.1200/JCO.2012.44.5486 PMID: 23091098

5. Marra E, Lin C, Clifford GM. Type-specific anal human papillomavirus prevalence among men, according to sexual preference and HIV status: a systematic literature review and meta-analysis. J Infect Dis. 2019;219(4):590-8. https://doi. org/10.1093/infdis/jiy556 PMID: 30239749

6. European Centre for Disease Prevention and Control (ECDC). Guidance on HPV vaccination in EU countries: focus on boys, people living with HIV and 9-valent HPV vaccine introduction
2020. Stockholm: ECDC; 2020. Available from: https://www. ecdc.europa.eu/sites/default/files/documents/Guidance-onHPV-vaccination-in-EU-countries2020-03-30.pdf

7. Nguyen-Huu NH, Thilly N, Derrough T, Sdona E, Claudot F, Pulcini $C$, et al. Human papillomavirus vaccination coverage, policies, and practical implementation across Europe. Vaccine. 2020;38(6):1315-31. https://doi.org/10.1016/j. vaccine.2019.11.081 PMID: 31836255

8. Shield KD, Marant Micallef C, de Martel C, Heard I, Megraud F, Plummer M, et al. New cancer cases in France in 2015 attributable to infectious agents: a systematic review and meta-analysis. Eur J Epidemiol. 2018;33(3):263-74. https://doi. org/10.1007/s10654-017-0334-Z PMID: 29214413

9. Avis du comite technique des vaccinations et du conseil superieur d'hygiene publique de France, section des maladies transmissibles, relatif à la vaccination contre les papillomavirus humains $6,11,16$ et 18 (séances du 9 mars 2007). [Opinion of the technical committee for vaccinations and the French high council for public health (transmissible disease) on vaccination against human papillomaviruses 6 , 11,16 and 18 (meeting on 9 March 2007)]. Paris: Ministère des Solidarités et de la Santé; 2007. French. Available from: https://www.hcsp.fr/docspdf/cshpf/a_mt_090307_ papillomavirus.pdf

10. Haut Conseil de la Santé Publique (HCSP). Avis relatif à la révision de l'âge de vaccination contre les infections à papillomavirus humains des jeunes filles. [Opinion on the revision of the age of vaccination against human papillomavirus infections of young girls]. Paris: HCSP; 2012 French. Available from: https://www.hcsp.fr/explore.cgi/ avisrapportsdomaine?clefr $=302$

11. Haut Conseil de la Santé Publique (HCSP). Avis relatif à l'utilisation du vaccin contre les infections à papillomavirus humains Gardasil. [Opinion on the use of the vaccine against human papillomavirus infections Gardasil]. Paris: HCSP; 2014. French. Available from: https://www.hcsp.fr/explore.cgi/ avisrapportsdomaine?clefr $=416$

12. Haut Conseil de la Santé Publique (HCSP). Vaccination des personnes immunodéprimées ou aspléniques. Recommandations actualisées. [Vaccination of immunocompromised or asplenic people. Updated recommendations]. Paris: HCSP; 2014. French. Available from: https://www.hcsp.fr/explore.cgi/ avisrapportsdomaine?clefr $=504$

13. Haut Conseil de la Santé Publique (HCSP). Recommandations vaccinales contre les infections à papillomavirus humains chez les hommes. [Vaccination recommendations against human papillomavirus infections in men]. Paris: HCSP; 2016. French. Available from: https://www.hcsp.fr/explore.cgi/ avisrapportsdomaine?clefr $=553$

14. Haut Conseil de la Santé Publique (HCSP). Avis relatif aux recommandations vaccinales contre les infections à papillomavirus humains chez les hommes. [Opinion on vaccine recommendations against human papillomavirus infections in men]. Paris: HCSP; 2016. French. Available from

15. Conseil nationale du SIDA et des hépatites virales (CNS). Stretégie nationale de santé sexuelle - Agenda 2017 - 2030-31 Mars 2017. In.; 2017. French. Available from: https://www.hcsp. $\mathrm{fr} /$ explore.cgi/avisrapportsdomaine? $\mathrm{clefr}=553$

16. Collège de la Haute Autorité de santé (HAS). Décision $n^{\circ}$ 2019.0280/DC/SEESP du 11 décembre 2019 du collège de la Haute Autorité de santé portant adoption de la recommandation vaccinale «Elargissement de la vaccination contre les papillomavirus aux garçons » et de son document de synthèse. [Decision no. 2019.0280/DC/SEESP of 11 December 2019 of the College of the High Authority for Health adopting the vaccine recommendation "Extension of vaccination against papillomavirus to boys" and its summary document]. Saint-Denis: HAS; 2019. French. Available from: https://www. has-sante.fr/jcms/p 3135808/fr/decision-n-2019-0280/dc/ seesp-du-11-decembre-2019-du-college-de-la-haute-autoritede-sante-portant-adoption-de-la-recommandation-vaccinaleelargissement-de-la-vaccination-contre-les-papillomavirusaux-garcons-et-de-son-document-de-synthese

17. Santé Publique France. Lieux de vaccination. Saint-Maurice: Santé Publique France; 2019. Available from: https:// professionnels.vaccination-info-service.fr/Aspects-pratiques/ Acte-vaccinal/Lieux-de-vaccination

18. https://professionnels.vaccination-info-service.fr/Aspectspratiques/Acte-vaccinal/Lieux-de-vaccination(HCSP). Recommandations vaccinales contre les infections à papillomavirus humains chez les hommes. [Vaccination recommendations against human papillomavirus infections in men]. Paris: HCSP; 2016. French. Available from: https://www. hcsp.fr/explore.cgi/avisrapportsdomaine?clefr $=552$

19. Pioche CNN, Sarr A, Cazein F, Bruyand M, Viriot D, et al. Activité de dépistage et diagnostic du VIH, des hépatites $B$ et $C$, et des autres IST en CeGIDD, France, 2018. [Screening 
for and diagnosis of HIV, hepatitis B and C and other STI in CeGIDD, France, 2018]. Bull Epidemiol Hebd (Paris). 2019;3132:625-33. French.

20. Duchesne L, Lydié N, Velter A: Increase in the overall level of protected anal sex in men who have sex with men in France: results from the repeated cross-sectional survey Rapport au Sexe, France, 2017-2019. AIDS Care. 2020;32(sup2):162-9.

21. Petit B, Epaulard O. Men having sex with men and the HPV vaccine in France: A low vaccine coverage that may be due to its infrequent proposal by physicians. Vaccine. 2020;38(9):2160-5. https://doi.org/10.1016/j. vaccine.2020.01.049 PMID: 32008880

22. Collège de la Haute Autorité de santé (HAS). Recommandation vaccinale - Élargissement de la vaccination contre les papillomavirus aux garçons. [Vaccination recommendation Expansion of vaccination against papillomaviruses to boys]. Saint-Denis: HAS; 2019. French. Available from: https:// www.has-sante.fr/jcms/p $3116022 / \mathrm{fr} / \mathrm{recommandation-sur-}$ l-elargissement-de-la-vaccination-contre-les-papillomavirusaux-garcons

23. Human papillomavirus vaccines: WHO position paper, May 2017. Wkly Epidemiol Rec. 2017;92(19):241-68. PMID: 28530369

24. Immunize BC. HPV (human papillomavirus). Victoria: Public Health Association of BC. [Accessed: 3 Sep 2020]. Available from: https://immunizebc.ca/hpv

25. National Immunisation Advisory Committee (NIAC). HPV vaccine for people with HIV and MSM. Dublin: NIAC; 2018. Available from: https://www.hse.ie/eng/health/immunisation/ hcpinfo/othervaccines/hpvadults

26. Edelstein M, lyanger N, Hennessy N, Mesher D, Checchi M, Soldan K, et al. Implementation and evaluation of the human papillomavirus (HPV) vaccination pilot for men who have sex with men (MSM), England, April 2016 to March 2017. Euro Surveill. 2019;24(8):1800055. https://doi.org/10.2807/15607917.ES.2019.24.8.1800055 PMID: 30808443

27. Oliver SE, Hoots BE, Paz-Bailey G, Markowitz LE, Meites E, NHBS Study Group. Increasing human papillomavirus vaccine coverage among men who have sex with men-national HIV behavioral surveillance, United States, 2014. J Acquir Immune Defic Syndr. 2017;75(Suppl 3):S370-4. https://doi.org/10.1097/ QAI.0000000000001413 PMID: 28604441

28. Loretan C, Chamberlain AT, Sanchez T, Zlotorzynska M, Jones J. Trends and characteristics associated with human papillomavirus vaccination uptake among men who have sex with men in the United States, 2014-2017. Sex Transm Dis. 2019;46(7):465-73. https://doi.org/10.1097/ OLQ.0000000000001008 PMID: 30994522

29. Gerend MA, Madkins K, Phillips G 2nd, Mustanski B. Predictors of human papillomavirus vaccination among young men who have sex with men. Sex Transm Dis. 2016;43(3):185-91. https://doi.org/10.1097/OLQ.0000000000000408 PMID: 26859806

30. Kellogg TA, Hecht J, Bernstein K, McFarland W, Connors A, Perloff $L$, et al. Comparison of HIV behavioral indicators among men who have sex with men across two survey methodologies, San Francisco, 2004 and 2008. Sex Transm Dis. 2013;40(9):689-94. https://doi.org/10.1097/01. olq.0000431354.96087.50 PMID: 23945424

31. Marcus U, Hickson F, Weatherburn P, Schmidt AJ, EMIS network. Age biases in a large HIV and sexual behaviourrelated internet survey among MSM. BMC Public Health. 2013;13(1):826. https://doi.org/10.1186/1471-2458-13-826 PMID: 24020518

32. Méthy N, Velter A, Semaille C, Bajos N. Sexual behaviours of homosexual and bisexual men in France: a generational approach. PLoS One. 2015;10(3):e0123151-0123151. https:// doi.org/10.1371/journal.pone.0123151 PMID: 25816322

33. Gorbach PM, Cook R, Gratzer B, Collins T, Parrish A, Moore J, et al. Human papillomavirus vaccination among young men who have sex with men and transgender women in 2 US cities, 2012-2014. Sex Transm Dis. 2017;44(7):436-41. https://doi. org/10.1097/OLQ.0000000000000626 PMID: 28608795

34. Rey D, Fressard L, Cortaredona S, Bocquier A, Gautier A, Peretti-Watel $P$, et al. Vaccine hesitancy in the French population in 2016, and its association with vaccine uptake and perceived vaccine risk-benefit balance. Euro Surveill. 2018;23(17):17-00816. https://doi.org/10.2807/1560-7917. ES.2018.23.17.17-00816 PMID: 29717693

35. Verrier F, Gautier A, Quelet S, Bonmarin I, et le groupe Baromètre de Santé publique France 2016. Infections à papillomavirus humain: influence des perceptions de la maladie et du vaccin sur le statut vaccinal. [Human papillomavirus infections: influence of perceptions of disease and vaccine on immunisation status]. Bull Epidémiol Hebd. 2019;(22-23):450-6.French.
36. Kahle EM, Meites E, Sineath RC, Nasrullah M, Bowles KE, DiNenno E, et al. Sexually transmitted disease testing and uptake of human papillomavirus vaccine in a large online survey of US men who have sex with men at risk for HIV infection, 2012. Sex Transm Dis. 2017;44(1):62-6. https://doi. org/10.1097/OLQ.0000000000000545 PMID: 27898576

37. Santé Publique France. Calendrier des vaccinations et recommandations vaccinales 2019. [Vaccination schedule and vaccine recommendations 2019]. Saint-Maurice: Santé Publique France; 2019. French. Available from: https:// solidarites-sante.gouv.fr/IMG/pdf/calendrier_vaccinal_ mars_2019.pdf

38. Santé Publique France. Hommes ayant des relations sexuelles avec des hommes. [Men who have sex with men]. Saint-Maurice: Santé Publique France; 2018. French. Available from: https://professionnels.vaccination-infoservice.fr/Recommandations-vaccinales-specifiques/ Personnes-exposees-a-des-risques-specifiques/ Hommes-ayant-des-relations-sexuelles-avec-des-hommes

39. Potherat GTJ, Epaulard O. Les hommes ayant des rapports sexuels avec des hommes et la médecine générale: mention de l'orientation sexuelle par les patients et impact sur la relation de soin (étude HomoGen). Bull Epidemiol Hebd (Paris). 2019;2019(12):204-10.

40. Chow EPF, Aung ET, Chen MY, Bradshaw CS, Fairley CK. Human papillomavirus vaccination and sexual practices among men who have sex with men in Melbourne, Australia: a crosssectional study. Int J STD AIDS. 2020;31(4):312-7. https://doi. org/10.1177/0956462419897514 PMID: 32063135

41. Haute Autorité de Santé. (HAS). La prophylaxie pré-exposition (PrEP) au VIH par ténofovir disoproxil/emtricitabine (TRUVADA et ses génériques). [HIV pre-exposure prophylaxis (PrEP) with tenofovir disoproxil/emtricitabine (TRUVADA and its generics)]. Saint-Denis: HAS; 2019. French. Available from: https://www. has-sante.fr/upload/docs/application/pdf/2019-05/bum_ truvada_maj_avril2019.pdf

42. Meunier É, Siegel K. Sex club/party attendance and STI among men who have sex with men: results from an online survey in New York City. Sex Transm Infect. 2019;95(8):584-7. https:// doi.org/10.1136/sextrans-2018-053816 PMID: 30867250

\section{License, supplementary material and copyright}

This is an open-access article distributed under the terms of the Creative Commons Attribution (CC BY 4.0) Licence. You may share and adapt the material, but must give appropriate credit to the source, provide a link to the licence and indicate if changes were made.

Any supplementary material referenced in the article can be found in the online version.

This article is copyright of the authors or their affiliated institutions, 2021. 